\title{
$e-\mathrm{Xtra}^{*}$
}

\section{Development and Application of qPCR and RPA Genus- and Species-Specific Detection of Phytophthora sojae and P. sansomeana Root Rot Pathogens of Soybean}

J. Alejandro Rojas, Department of Plant, Soil and Microbial Sciences, Michigan State University, East Lansing, 48824; and Program in Ecology, Evolutionary Biology and Behavior, Michigan State University, East Lansing, 48824; Timothy D. Miles, School of Natural Sciences, California State University, Monterey Bay, Seaside, 93955; Michael D. Coffey, Department of Plant Pathology and Microbiology, University of California, Riverside, 92521; Frank N. Martin, United States Department of Agriculture-Agricultural Research Service, Crop Improvement and Protection Research Unit, Salinas, CA 93905; and Martin I. Chilvers, Department of Plant, Soil and Microbial Sciences, Michigan State University, East Lansing, 48824; and Program in Ecology, Evolutionary Biology and Behavior, Michigan State University, East Lansing, 48824

\begin{abstract}
Phytophthora root rot of soybean, caused by Phytophthora sojae, is one of the most important diseases in the Midwestern United States, and is estimated to cause losses of up to 1.2 million metric tons per year. Disease may also be caused by $P$. sansomeana; however, the prevalence and damage caused by this species is not well known, partly due to limitations of current diagnostic tools. Efficient, accurate, and sensitive detection of pathogens is crucial for management. Thus, multiplex qPCR and isothermal RPA (recombinase polymerase amplification) assays were developed using a hierarchical approach to detect these Phytophthora spp. The assays consist of a genus-specific probe and two species-specific probes that target the atp9-nad 9 region of the mitochondrial genome that is highly specific for the genus Phytophthora. The qPCR approach multiplexes the three probes and a plant internal control.

The RPA assays run each probe independently with a plant internal control multiplexed in one amplification, obtaining a result in as little as 20 mins. The multicopy mitochondrial genome provides sensitivity with sufficient variability to discern among different Phytophthora spp. The assays were highly specific when tested against a panel of 100 Phytophthora taxa and range of Pythium spp. The consistent detection level of the assay was $100 \mathrm{fg}$ for the qPCR assay and $10 \mathrm{pg}$ for the RPA assay. The assays were validated on symptomatic plants collected from Michigan (U.S.) and Ontario (Canada) during the 2013 field season, showing correlation with isolation. In 2014, the assays were validated with samples from nine soybean producing states in the U.S. The assays are valuable diagnostic tools for detection of Phytophthora spp. affecting soybean.
\end{abstract}

Phytophthora root and stem rot of soybean is one of the most prevalent and widely distributed soybean diseases, causing reduced yield and worldwide estimated losses of ca. 2.3 million metric tons per year (Erwin and Ribeiro 1996; Wrather et al. 2010). Phytophthora sojae, the main causal agent of this damaging disease, was initially reported in the mid-1950s in the Midwest region of the United States (Kaufmann and Gerdemann 1958), and has since become a major concern for soybean production causing annual estimated losses of 1.2 million metric tons (Wrather et al. 2010). P. sojae is an oomycete pathogen that survives in the soil as oospores. Under optimal conditions, oospores germinate and infect seeds and roots, causing seed rot and damping-off of seedlings. $P$. sojae may also cause root and stem rot that results in wilting and plant death. While the typical brown to purple water-soaked lesions on the stem appear mid to late season on infected plants, early season infection may also result in an uneven plant stand and possibly require replanting (Bienapfl et al. 2011; Dorrance et al. 2009).

Disease symptoms such as root rot, wilting, and seedling dampingoff at early plant development stages are not distinguishable from those caused by other soil-borne pathogens, such as Pythium, Rhizoctonia, and Fusarium spp. (Rizvi and Yang 1996). Without

Corresponding author: Martin Chilvers; E-mail: chilvers@msu.edu

Frank N. Martin and Martin Chilvers contributed equally to this work.

*The $\boldsymbol{e}$-Xtra logo stands for "electronic extra" and indicates that eight supplementary tables, three supplementary figures, and two supplementary sequences are available online.

Accepted for publication 8 March 2017.

(c) 2017 The American Phytopathological Society the presence of the stem lesion that occurs midseason, the diagnosis of Phytophthora root rot requires laborious isolation and identification of the causal agent. However, isolation of the pathogen at early stages is often challenging and lengthy due to the slow growth of $P$. sojae and secondary colonization by other fungi and oomycetes on the plant tissue that outgrow P. sojae on the medium. Confounding diagnosis further, a new oomycete species was reported as a soybean root pathogen in the early 1990s, but not formerly described until 2009 as P. sansomeana (Hamm and Hansen 1981; Hansen et al. 2009; Malvick and Grunden 2004; Reeser et al. 1991). P. sansomeana is a homothallic pathogen that causes damping-off of soybean, but also infects a broad host range such as corn, Douglas-fir, alfalfa, and some weed species (Hansen et al. 2009; Malvick and Grunden 2004; Zelaya-Molina et al. 2010). In contrast to P. sansomeana, $P$. sojae has a very narrow host range with soybean as the main host (Erwin and Ribeiro 1996) and is classified in clade $7 \mathrm{~b}$ along with $P$. cinnamomi, $P$. vignae, and $P$. niederhauserii, which is different from $P$. sansomeana in clade 8a grouping with $P$. cryptogea, P. drechsleri, and P. medicaningis (Martin et al. 2014; O'Brien et al. 2009). In addition, $P$. sansomeana has not been associated with cultivar specificity, unlike $P$. sojae, where pathotypes have been established based on cultivars with specific resistance genes (Hansen et al. 2012). The similar symptoms caused by other Phytophthora spp. and other oomycetes in soybean seedlings complicates diagnostics, reinforcing the need for an accurate and sensitive assay to diagnose these causal agents.

Detection of Phytophthora spp. for diagnostic purposes in the field and/or laboratory has focused on the use of enzyme-linked immunosorbant assays (ELISA) for an initial and rapid assessment of diseased plant samples. The ELISA detection assay from Agdia Inc. employs polyclonal antibody against Phytophthora spp. with limited sensitivity (O'Brien et al. 2009). ELISA sensitivity threshold for different Phytophthora spp. was reported at $0.1 \mathrm{ng}$ of freeze dried mycelia (Bowman et al. 2007). ELISA is less specific than PCR, due to 
cross-reactivity with other oomycetes, such as Pythium, a common root rot seedling pathogen of soybean (Agdia 2016; O'Brien et al. 2009; Wrather et al. 2010). The lack of species-specific detection results in limited diagnostic capability and limits specific management recommendations, such as use of resistant varieties or seed treatments, and our knowledge of the prevalence of $P$. sansomeana as a soybean pathogen. In addition to ELISA, conventional PCR and qPCR are two of the main approaches broadly used to diagnose and quantify plant pathogens. Wang et al. (2006) developed a P. sojae conventional PCR assay targeting the internal transcribed spacer (ITS) of the ribosomal DNA (rDNA). The same primer set for P. sojae was also adapted in a SYBR Green assay for pathogen quantification with a claimed detection level of $1 \mathrm{fg}$ of genomic DNA; however, the assay showed limited specificity when challenged with multiple Phytophthora spp. (Bienapfl et al. 2011; Wang et al. 2006). Bienapfl et al. (2011) developed a second assay for conventional PCR and qPCR. This assay targeted the ITS region of the rDNA, with a sensitivity of $10 \mathrm{pg}$ in conventional PCR and $1 \mathrm{pg}$ when used in a SYBR Green qPCR assay. Catal et al. (2013) reported a detection level of $10 \mathrm{fg}$ for the same assay. However, specificity of the assay was only challenged with a limited number of Phytophthora spp., including some species from Clade 7.

The availability of isothermal DNA amplification techniques has opened a new field for the development and application of diagnostics for plant pathogens (Fukuta et al. 2013, 2014; Hansen et al. 2016; Kubota et al. 2008; Li et al. 2015; Miles et al. 2015; Yan et al. 2014). The isothermal techniques present a new framework, where rapid and simple detection of pathogens can be made since the reaction is incubated at constant temperature, thereby simplifying required instrumentation. As a consequence of minimal requirements, isothermal diagnostic methods could be conducted directly in the field. An example of this is loop-mediated isothermal amplification (LAMP), which is mediated by a set of four primers that form hairpin-like structures that facilitate amplification (Yan et al. 2014). Dai et al. (2012) developed a P. sojae LAMP assay that targets a transposonlike element in the promoter region of the virulence gene $A v r 3 a$, which is a unique element of the $P$. sojae genome. The specificity of this LAMP assay was tested against 10 Phytophthora spp. and Pythium ultimum and the sensitivity of this assay on pure genomic DNA was established at $20 \mathrm{pg}$. To the best of our knowledge, no assays, either qPCR or isothermal, have been developed to detect $P$. sansomeana.

The recent development of a hierarchical approach of Phytophthora genus- and species-specific qPCR assays based on mitochondrial genes by Bilodeau et al. (2014) provides a novel system for diagnostics. This approach utilized two loci, one for the purposes of amplifying all Phytophthora spp. (trnM-trnP-trnM), and the other one capable of genus- and species-specific detection (atp9-nad9). This resulted in the development and validation of two genusspecific assays and species-specific TaqMan probes for 13 Phytophthora spp. plus the $P$. citricola complex. The same approach also can be further utilized to design unique probes for many Phytophthora spp. as demonstrated by Miles et al. (2017). Miles et al. (2015) adapted the marker system to work with an isothermal technique known as recombinase polymerase amplification (RPA, TwistDx Ltd., Cambridge, U.K.), which produces results in little as $15 \mathrm{~min}$. The RPA is an isothermal-based technique where annealing and amplification occur at the same temperature (any temperature between 39 and $42^{\circ} \mathrm{C}$ ), eliminating temperature-based specificity. The process starts by forming a primer-enzyme complex, which consists of a recombinase and primers (optimal size of 30 to $35 \mathrm{bp}$ ), that recognizes homologous regions on the target DNA, resulting in the formation of a replication loop on the double stranded DNA. This process is aided by the binding of single-strand binding proteins, leading to the amplification by DNA polymerase, which also recognizes and binds the homologous region. Fluorometric RPA assays, like the ones developed in Miles et al. (2015), utilize highly modified probes during this amplification that are partially cleaved at the abasic site analog tetrahydrofuran (THF) by an endonuclease type VI, releasing the fluorophore and displacing the $3^{\prime}$ side of the probe that contained a $\mathrm{C} 3$ spacer block. Therefore, the $5^{\prime}$ end of the probe becomes a primer also used during the amplification process (Piepenburg et al. 2006; Yan et al. 2014). The RPA assay is similar to conventional PCR achieving exponential endpoint amplification. However, RPA assays are more tolerant of contaminants present than conventional PCR assays, making them more robust on crude samples. Furthermore, these assays typically occur within a 20 min timeframe as opposed to $2 \mathrm{~h}$ for a typical PCR assay. Miles et al. (2015) developed a genusspecific assay for Phytophthora spp. and two species-specific assays (P. ramorum and $P$. kernoviae), showing the flexibility of this system for designing assays for Phytophthora spp.

To improve diagnostic assays available for $P$. sojae and $P$. sansomeana, we built upon the approaches described by Bilodeau et al. (2014), Miles et al. (2015), and Miles et al. (2017). The objectives of this research were to: (i) develop a robust, sensitive, and specific multiplex qPCR assay for $P$. sojae and $P$. sansomeana at speciesspecific level; (ii) design a species-specific RPA assay for both $P$. sojae and $P$. sansomeana; (iii) evaluate the cross-platform transferability of the assays; and (iv) validate the field application of assays with paired plant and soil samples collected in 2013 and 2014.

\section{Materials and Methods}

Phytophthora sojae and $\boldsymbol{P}$. sansomeana isolates. Isolates were obtained from diseased soybean seedlings using a semiselective medium CMA-PARPB (Jeffers 1986) as part of a 12-state survey (2011 and 2012) to identify oomycete species causing soybean seedling diseases (Rojas et al. 2017a, b). Additional isolates for both species were obtained from the World Phytophthora Genetic Resource Collection (University of California, Riverside), Embrapa Trigo (Passo Fundo, RS, Brazil), and Dr. Everett Hansen at Oregon State University to account for genetic variability across geographic locations and hosts (Supplementary Table S1). Isolates were grown and maintained on semiselective CMA-PARPB medium. Mycelia were grown in clarified V8 juice broth (100 ml of clarified V8 juice, $1 \mathrm{~g}$ of $\mathrm{CaCO}_{3}$, and $900 \mathrm{ml}$ of water) for 5 days, then harvested and lyophilized for DNA extraction. Freeze-dried mycelia were ground and $40 \mathrm{mg}$ of ground mycelia were used for DNA extraction with DNeasy Plant Mini Kit (Qiagen, Valencia, CA). DNA concentration and quality were evaluated with a Nanodrop ND-1000 (Thermo-Fisher Scientific, Waltham, MA).

qPCR probe design for $P$. sojae and $P$. sansomeana. The mitochondrial locus atp9-nad 9 was used to design the species-specific probes due to the interspecific polymorphisms across a range of taxa (Bilodeau et al. 2014; Miles et al. 2017). The locus atp9-nad9 was amplified and sequenced using the primers Nad9-F and Nad9-R (Table 1) described by Martin et al. (2014) for all the P. sojae and $P$. sansomeana isolates. The target locus was amplified in a $25 \mu 1 \mathrm{re}-$ action volume containing $1 \times$ DreamTaq Buffer (Thermo Fisher Scientific), $200 \mu \mathrm{M}$ dNTPs (Life Technologies, Carlsbad, CA), $0.2 \mu \mathrm{M}$ of Nad9-F and Nad9-R primers (Table 1), $0.1 \mathrm{mg} / \mathrm{ml} \mathrm{BSA}$, and 1 unit of DreamTaq polymerase (Thermo Fisher Scientific). Thermal cycling consisted of denaturation at $95^{\circ} \mathrm{C}$ for $3 \mathrm{~min} ; 35$ cycles at $95^{\circ} \mathrm{C}$ for $1 \mathrm{~min}, 61^{\circ} \mathrm{C}$ for $1 \mathrm{~min}$, and $72^{\circ} \mathrm{C}$ for $1 \mathrm{~min}$; and final extension at $72^{\circ} \mathrm{C}$ for $10 \mathrm{~min}$. Products were visualized on $1 \%$ agarose gels stained with ethidium bromide. Amplification products were cleaned using 3U/reaction of Exonuclease I (ExoI, Thermo Fisher Scientific) and $0.5 \mathrm{U} /$ reaction of Shrimp alkaline phosphatase (SAP, Thermo Fisher Scientific) and incubated at $37^{\circ} \mathrm{C}$ for $40 \mathrm{~min}$. Treated PCR products were submitted to Macrogen USA for sequencing (MacrogenUSA, Rockville, MD). Each template was sequenced in both directions, and CodonCode Aligner (CodonCode Corporation, Centerville, MA) was used to assemble, edit, and generate the consensus sequences.

Sequences for $P$. sojae and $P$. sansomeana isolates were aligned with MUSCLE in Geneious 4.7.6 (Biomatters Ltd., Auckland, New Zealand) and evaluated for polymorphism at the intraspecies level for design of species-specific probes. In addition, the probe design was refined by aligning $P$. sojae and $P$. sansomeana sequences against sequences of 91 valid Phytophthora spp. and 30 putative Phytophthora taxa (Bilodeau et al. 2014). Species-specific probes 
were developed based on highly polymorphic regions using the following parameters: (i) melting temperature $5^{\circ} \mathrm{C}$ higher than the amplification primers; (ii) 15 to 36 nucleotides in length with no more than two Gs or $\mathrm{Cs}$ in the last five nucleotides from the $3^{\prime}$ end; and (iii) mismatched nucleotides positioned in the center of the probe to avoid secondary structures. Two hydrolysis probes were designed: the $P$. sojae species-specific TaqMan probe was labeled with HEX at the $5^{\prime}$ end, an internal ZEN quencher, and $3^{\prime}$ Iowa Black FQ quencher (IDT, Coralville, IA); and the $P$. sansomeana species-specific TaqMan probe was labeled with Quasar670 at the 5' end, and 3' Black Hole Quencher-2 (BHQ-2) (Biosearch Technologies, Inc., Novato, CA).

qPCR conditions for $P$. sojae and $P$. sansomeana assay. The qPCR assays were performed on a CFX96 Real-Time PCR Detection System (BioRad Laboratories, Hercules, CA). The qPCR primers employed in this study were adapted from Bilodeau et al. (2014) and the Phytophthora genus-specific TaqMan probe labeled with FAM (fluorescein) at the $5^{\prime}$ end, an internal ZEN quencher, and $3^{\prime}$ end Iowa Black FQ quencher (Table 1). In addition, a plant internal control and internal control for soil samples were established. For the plant internal control, primers and probe developed by Bilodeau et al. (2014) were also included in the reaction, the probe was labeled at the 5' end with CalFluor Red 610 and Black Hole Quencher-2 (BHQ-2) at the $3^{\prime}$ end. Internal control for soil samples was adapted from Bilodeau et al. (2012), using the Pythium plasmid pUC96-4 and primers PPF1F and PPF1R, each of them with binding sites for the Phytophthora genus primers PhyG_ATP9_2FTail and PhyG-R6_Tail tailed on, respectively. Internal control was amplified using Phytophthora genus primers PhyG_ATP9_2FTail and PhyG-R6_Tail, the product was cleaned with the exonuclease and phosphatase as described previously, and diluted to $10^{-9}$ ( 0.2 to $0.3 \mathrm{fg} / \mu \mathrm{l}$, ca. 1,500 to 2,000 copies). Reactions were performed in a final volume of $20 \mu \mathrm{l}$ using the Real Master Mix without ROX (5 Prime; Fisher Scientific Company, LLC, Waltham, MA; currently sold as Perfecta Multi qPCR Tough Mix, cat. \# 89497-278). Reagent volumes per single reaction are shown in Supplementary Table S2, for plant and soil samples. The thermal cycling conditions were $95^{\circ} \mathrm{C}$ for $2 \mathrm{~min}, 50$ cycles at $95^{\circ} \mathrm{C}$ for $15 \mathrm{~s}$, and $57^{\circ} \mathrm{C}$ for $1 \mathrm{~min} 30 \mathrm{~s}$.

Evaluation of qPCR sensitivity and specificity. The assay specificity was tested against a panel of 110 Phytophthora taxa representing all 10 clades, including species closely related to $P$. sojae and $P$. sansomeana, that was composed of 96 valid species and 14 provisional species. The panel also included three different subspecies of $P$. alni (subsp. alni, multiformis, and uniformis), three phylogenetic groups of $P$. cryptogea (GI, GII, and sp. kelmania GIII), and six phylogenetically distinct species (sp. aff. brassicae-1, sp. aff. brassicae-2, sp. aff. colocasiae -1, sp. aff. erythroseptica, sp. aff. siskiyouensis, cinnamomi var. robiniae, and citricola clade E). All Phytophthora isolates were obtained and are available from the World Phytophthora Genetic Resource Collection at the University of California, Riverside (Supplementary Table S5). In addition, 21 Pythium spp. and Phytopythium vexans were included in the panel to validate the specificity. DNA was diluted to $1 \mathrm{ng} / \mu \mathrm{l}$ and used in the assay.

A 10-fold serial dilution of $P$. sojae (isolates IASO_8-13.10 and IASO_3-41.17) and $P$. sansomeana (isolates V-KSSO2_3-6 and MICO_3-24) DNA ranging from $10 \mathrm{ng}$ to $1 \mathrm{fg}$ were used as standards to determine sensitivity, establish amplification efficiency, and resolve the limit of detection (LOD). The $P$. sojae and $P$. sansomeana total DNA serial dilutions were prepared using $1 \mathrm{ng} / \mu \mathrm{l}$ salmon sperm DNA (Invitrogen) as a carrier DNA to minimize DNA loss through binding to plasticware or degradation. The DNA for the standard curve was quantified using Quant-iT dsDNA high-sensitivity assay kit (Invitrogen). For the real-time qPCR assay, PCR efficiency was calculated with the formula: $\mathrm{E}=10^{(-1 / \text { slope })}-1$. The LOD was determined following MIQE guidelines (Bustin et al. 2009). In addition, the effect of plant DNA was tested in conjunction with the DNA standards; $20 \mathrm{ng}$ of soybean DNA was spiked with the standards to determine the effect of DNA on the assay performance.

Cross-platform validation of $\mathbf{q P C R}$ assays. To test the crossplatform transferability of the assay, $P$. sojae and $P$. sansomeana total DNA serial dilution standards were assayed independently on three platforms: ABI StepOne Plus (Applied Biosystems, Foster City, CA), Roche LightCycler 96 (Roche Diagnostics, Mannheim, Germany), and Bio-Rad CFX96. All tests were conducted under the same reaction and cycling conditions for all platforms to validate the qPCR assay.

Development of RPA assays for $P$. sojae and $P$. sansomeana. Primers (TrnM-F and TrnM-R) and probe (TrnM-P) for the Phytophthora genus-specific assay were developed by Miles et al. (2015) and the sequences are listed in Table 2 . To develop a $P$. sojae and $P$. sansomeana species-specific RPA assay, the alignment of the atp9-nad9 region included multiple isolates of both species along with several Phytophthora spp. Primers were designed manually based on the Phytophthora spp. alignment following the recommendations

Table 1. Primers and probes used in this study for sequencing of the atp9-nad9 locus and Phytophthora sojae and P. sansomeana multiplex genus- and speciesspecific qPCR

\begin{tabular}{|c|c|c|c|c|}
\hline Primer/probes & Sequence $\left(5^{\prime}-3^{\prime}\right)$ & Length (nt) & GC\% & Target \\
\hline $\mathrm{Nad} 9-\mathrm{F}^{\mathrm{a}}$ & TACAACAAGAATTAATGAGAAC & 22 & 27.3 & atp9-nad9 \\
\hline Nad9-R ${ }^{a}$ & GTTAAAATTTGTACTACTAACAT & 23 & 21.7 & atp9-nad9 \\
\hline \multicolumn{5}{|l|}{ Primers } \\
\hline PhyG_ATP9_2FTail ${ }^{\text {b }}$ & AATAAATCATAACCTTCTTTACAACAAGAATTAATG & 36 & 22.2 & atp 9 \\
\hline PhyG-R6_Tail ${ }^{\mathrm{b}}$ & AATAAATCATAAATACATAATTCATTTTTATA & 32 & 9.4 & $\operatorname{nad} 9$ \\
\hline \multicolumn{5}{|c|}{ 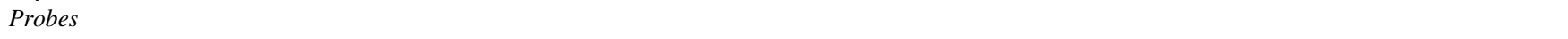 } \\
\hline $\begin{array}{l}\text { Phytophthora genus-specific } \\
\text { TaqMan probe }\end{array}$ & [FAM] AAAGCCATC [ZEN] ATTAAACARAATAAAGC [IABkFQ] & 26 & 28.8 & atp9-nad 9 \\
\hline $\begin{array}{l}\text { P. sojae species-specific } \\
\text { TaqMan probe }\end{array}$ & [HEX] TTGATATAT [ZEN] GAATACAAAGATAGATTTAAGTAAAT [IABkFQ] & 35 & 17.1 & atp9-nad9 \\
\hline $\begin{array}{l}\text { P. sansomeana } \\
\text { species-specific } \\
\text { TaqMan probe }\end{array}$ & [Quasar670] TATTAGTACTAAYTACTAATATGCATTATTTTTAG [BHQ-2] & 35 & 18.6 & atp9-nad 9 \\
\hline \multicolumn{5}{|l|}{ Plant Internal Control } \\
\hline FMPI $2 b^{b}$ & GCGTGGACCTGGAATGACTA & 20 & 55.0 & $\operatorname{cox} \mathrm{I}$ \\
\hline FMPI $3 b^{b}$ & AGGTTGTATTAAAGTTTCGATCG & 23 & 34.8 & $\operatorname{cox} \mathrm{I}$ \\
\hline $\begin{array}{l}\text { Plant-IC probe } \\
\text { Internal Control (Soil) }\end{array}$ & [CalFluorRed610] CTTTTATTATCACTTCCGGTACTGGCAGG [BHQ-2] & 29 & 44.8 & $\operatorname{cox} \mathrm{I}$ \\
\hline $\mathrm{PPF}^{\mathrm{d}}$ & [CalFluorRed610] AAAGTAAGCTTATCGATACCGTCGACCT [BHQ-2] & 28 & 42.9 & Internal control $^{\mathrm{C}}$ \\
\hline
\end{tabular}

\footnotetext{
a Primers reported by Martin et al. (2014).

${ }^{\mathrm{b}}$ Primers and probes reported by Bilodeau et al. (2014).

${ }^{\mathrm{c}}$ Modified from Bilodeau et al. (2014).

d Adapted from Bilodeau et al. (2012).
} 
provided in the TwistAmp exo kit (TwistDx, Babraham, Cambridge, U.K.). The assay uses a general Phytophthora forward primer (Atp9-F) located in the atp9 region (Miles et al. 2015) and species-specific reverse primer (Psojae-nad9-R or Psan-nad9-R) placed in the atp9nad 9 spacer region (Table 2). Detection was based on a Phytophthora genus-specific probe (Miles et al. 2015), which has the following characteristics: 46 to $52 \mathrm{bp}$ long, where 30 bases are on the $5^{\prime}$, follow by fluorophore (FAM) and quencher (Black Hole Quencher-1, BHQ-1) separated 2 to 4 bases from each other, and a tetrahydrofuran abasic site (THF) replacing a base in between fluorophore and quencher; and finally a $\mathrm{C} 3$ spacer block that prevents amplification. When used on plant samples, a plant internal control was also included in the multiplex assay for plant samples. Primers (CoxI-IPC-F and CoxI-IPC-R) and probe (CoxI-IPC-P) were developed by Miles et al. (2015) and their sequences are listed in Table 2. Primers were obtained from Integrated DNA Technologies, Inc. (Coralville, IA) and probes were synthesized from Biosearch Technologies, Inc. (Novato, CA).

RPA amplification conditions for $P$. sojae and $P$. sansomeana. Isothermal amplification was conducted using TwistAmp exo kit (TwistDx) and two platforms were used for the RPA assays incubation and detection: Twista (TwistDx) and Smart-DART device (Diagenetix, Inc., Honolulu, HI). The Phytophthora genus-specific RPA reaction was conducted as reported by Miles et al. (2015); the reagents and sample volumes are listed in Supplementary Table S3. The reaction mix was then transferred into a TwistAmp exo kit reaction tube containing the lyophilized reagents, and mixed well to dissolve the lyophilized enzymes. To initiate the reaction, $2.5 \mu \mathrm{l}$ of $280 \mathrm{mM}$ magnesium acetate was placed on the cap, closed carefully, and spun briefly. For the Phytophthora species-specific RPA assay, a $50-\mu l$ reaction was set up following the procedure described above. Initiated reactions were incubated at $39^{\circ} \mathrm{C}$ for $4 \mathrm{~min}$, tubes were removed, mixed by inversion, spun briefly, and placed into the detection unit for $25 \mathrm{~min}$ at $39^{\circ} \mathrm{C}$. Fluorescence was collected every $20 \mathrm{~s}$ following manufacturer's recommendations.

RPA assays sensitivity and specificity. The specificity was tested against the same panel of Phytophthora spp., Pythium spp., and Phytopythium vexans used for the qPCR assay. DNA was diluted to $1 \mathrm{ng} /$ $\mu l$ and $1 \mu \mathrm{l}$ from five species was pooled and tested for specificity. If cross-reactivity was observed, species were tested individually. Sensitivity for the RPA assay was determined with standard serial dilutions ranging from $10 \mathrm{ng}$ to $1 \mathrm{fg}$ prepared as described above. Standard curve plots were constructed based on the log transformed DNA concentration and the onset of amplification threshold (OT) for each concentration. The OT was established using a slope validation, where four time points had an overall slope higher than $30 \mathrm{mV} / \mathrm{min}$.

Collection of field samples and assay field application. To validate qPCR and RPA assays, field samples were collected in 2013 and 2014 from soybean fields with damping-off and root rot symptomatic plants. In 2013, 16 fields across Michigan and Ontario were sampled, and 42 plant samples and 16 composite soil samples were collected (Table 3). Symptomatic plant samples were plated on semiselective medium CMA-PARPB to isolate $P$. sojae or P. sansomeana, and plant samples were also tested with a Phytophthora ELISA Kit (SRA 92601; Agdia, Inc., Elkhart, IN). In 2014, extensive sampling was conducted across nine soybean-producing states in the Midwest with collaborators of the USDA-NIFA Oomycete Soybean Coordinated Agricultural Project (Table 4). A total of 23 fields, consisting of one to three fields per state, were sampled; paired plant and soil samples were collected at each field location, resulting in 73 plant samples and 18 composite soil samples. Samples were transported in coolers and shipped overnight to Michigan State University. No isolations were performed on the 2014 plant samples.

DNA extraction from soybean roots. Collected soybean roots with or without visible symptoms of root rot were washed with tap water and blotted dry with paper towels. Plants from each location were divided into three biological replicates consisting of five plants. Roots of each of the three biological subsamples were cut longitudinally; one half was stored at $-20^{\circ} \mathrm{C}$ for later use with the RPA assay. The second half was air-dried, ground using a Wiley mill (1 mm screen), and then used for DNA extraction. DNA was isolated following the standard USDA-APHIS procedure for P. ramorum (USDA-APHIS 2004) employing Qiagen DNeasy kit (Qiagen).

DNA extraction from soil. DNA was extracted from three soil subsamples per field location using a FastDNA SPIN kit for soil (MP Bio, Solon, OH). Briefly, $400 \mathrm{mg}$ of soil were placed in a lysing matrix $\mathrm{E}$ tube, followed by addition of $978 \mu \mathrm{l}$ of phosphate buffer and $122 \mu \mathrm{l}$ of MT buffer. Tubes were homogenized in a FastPrep FP120 instrument (MP Bio) at speed 6 for $40 \mathrm{~s}$. DNA extraction was completed according to manufacturer's recommendations. Three independent DNA extractions were done. The recovered DNA was tested with multiplex qPCR assay undiluted and 10-fold diluted. To determine if PCR inhibitors or soil contamination was a problem, $25 \mu \mathrm{l}$ of DNA were purified using Mag-Bind E-Z Pure kit (Omega Bio-tek Inc., Norcross, GA). The fraction purified by paramagnetic beads was re-evaluated using the multiplex qPCR assay.

Crude extracts from soybean roots and RPA assay. Root samples preserved at $-20^{\circ} \mathrm{C}$ for the RPA assays were further subsampled into $0.5 \mathrm{~g}$ of root tissue. Root tissue was placed into plastic mesh sample bags (ACC 00930; Agdia Inc.) with 5 ml GEB2 extraction buffer dissolved according to the manufacturers recommendations (ACC 00130; Agdia Inc.) and macerated with a tissue homogenizer tool (ACC 00900; Agdia Inc.). Crude extracts were collected in centrifuge tubes and frozen at $-20^{\circ} \mathrm{C}$ for later use. Reactions were conducted as mentioned above.

Confirmation of Phytophthora spp. identity. To confirm the identity of Phytophthora spp. detected by the RPA genus-specific assay, but negative for the species-specific assay, amplifications were used to conduct a nested PCR as described by Miles et. al (2015). Briefly, $1 \mu l$

Table 2. Primers and probes used for Phytophthora sojae and P. sansomeana recombinase polymerase amplification (RPA) genus- and species-specific assay

\begin{tabular}{|c|c|c|c|c|}
\hline Primer/probes & Sequence $\left(5^{\prime}-3^{\prime}\right)$ & Length (nt) & GC\% & Target \\
\hline \multicolumn{5}{|c|}{ Phytophthora genus-specific } \\
\hline TrnM-Fa & ATGTAGTTTAATGGTAGAGCGTGGGAATC & 29 & 41.4 & tRNA-M \\
\hline $\operatorname{TrnM}-R^{\mathrm{a}}$ & GAACCTACATCTTCAGATTATGAGCCTGATAAG & 33 & 39.4 & tRNA-M \\
\hline TrnM-P (probe) $)^{\mathrm{a}}$ & $\begin{array}{l}\text { TAGAGCGTGGGAATCATAATCCTAATGTTG [FAM-dT] } \\
\text { A [THF] G [BHQ1-dT] TCAAATCCTACCATCAT [3'-C3SPACER] }\end{array}$ & 51 & 37.3 & tRNA-M \\
\hline \multicolumn{5}{|c|}{ Phytophthora species-specific } \\
\hline Atp9-F & ССТТСТTTACAACAAGAATTAATGAGAACCGCTAT & 35 & 34.3 & atp 9 \\
\hline Psojae-nad9-R & TTAAATCTATCTTTGTATTCATATATCAA & 29 & 17.2 & atp9-nad9 \\
\hline Psan-nad9-R & TTAGTAGTTAGTACTAATATAACAAAAATATAATA & 35 & 14.3 & atp9-nad9 \\
\hline Atp9-P (probe) $)^{\mathrm{a}}$ & $\begin{array}{l}\text { TTGCTTTATTYTGTTTAATGATGGCWTTY (T-FAM) T [THF] } \\
\text { A (T-BHQ1) YTTATTTGCTTTTT [3'-C3SPACER] }\end{array}$ & 47 & 22.3 & atp 9 \\
\hline \multicolumn{5}{|l|}{ Plant internal control } \\
\hline Cox1-IPC-Fa & CATGCGTGGACCTGGAATGACTATGCATAGA & 31 & 48.4 & $\operatorname{coxI}$ \\
\hline Cox1-IPC-R ${ }^{\mathrm{a}}$ & GGTTGTATTAAAGTTTCGATCGGTTAATAACA & 32 & 31.3 & $\operatorname{cox} \mathrm{I}$ \\
\hline Cox1-IPC-P (probe) ${ }^{\mathrm{a}}$ & $\begin{array}{l}\text { GGTCCGTTCTAGTGACAGCATTCCYACTTTTATTA [TAM-dT] } \\
\text { C [THF] C [BHQ2-dT] YCCGGTACTGGC [3'-C3SPACER] }\end{array}$ & 51 & 49 & $\operatorname{cox} \mathrm{I}$ \\
\hline
\end{tabular}

${ }^{a}$ Reported by Miles et al. (2015). 
of 10-fold dilution of RPA product was used as template, and amplified using primers Nad9_Fseq1 and Nad9Rseq1. Products were evaluated in agarose gel and processed for sequencing as described above.

\section{Results}

qPCR probe design for $\boldsymbol{P}$. sojae and $\boldsymbol{P}$. sansomeana. atp9-nad 9 sequences of $P$. sojae isolates from different geographic origins were aligned to evaluate intraspecific variation of this species across different locations around the world. No differences for this locus were observed among 53 isolates sequenced, which indicates that the assay could be used without limitations to identify $P$. sojae. A similar approach was carried out with 22 isolates of $P$. sansomeana, even though this species has only been reported in the U.S. and China. Since we only had access to U.S. isolates and P. sansomeana has

Table 3. Isolation, ELISA, multiplex qPCR and recombinase polymerase amplification (RPA) evaluation for Phytophthora genus and Phytophthora sojae and $P$. sansomeana species-specific assays of plant samples collected in Michigan and Ontario in 2013

\begin{tabular}{|c|c|c|c|c|c|c|c|c|c|c|c|}
\hline \multirow[b]{2}{*}{ Fields } & \multirow{2}{*}{$\begin{array}{l}\text { Number } \\
\text { samples }\end{array}$} & \multirow[b]{2}{*}{ Isolation $^{\mathbf{a}}$} & \multirow{2}{*}{$\begin{array}{l}\text { Phytophthora } \\
\text { ELISA }^{\mathrm{b}}\end{array}$} & \multirow{2}{*}{$\begin{array}{c}\text { Positives } \\
\text { qPCR genus }\end{array}$} & \multirow{2}{*}{$\frac{\text { Plant internal control }}{\text { Mean } \mathbf{C}_{\mathbf{t}}^{\mathbf{d}}}$} & \multicolumn{2}{|c|}{$\begin{array}{c}\text { Phytophthora } \\
\text { genus }\end{array}$} & \multicolumn{2}{|c|}{ P. sojae } & \multicolumn{2}{|c|}{ P. sansomeana } \\
\hline & & & & & & Mean $C_{t}$ & $\overline{\mathbf{R P A}^{\mathrm{e}}}$ & Mean $C_{t}$ & $\overline{\text { RPA }}$ & Mean $C_{t}$ & $\overline{\text { RPA }}$ \\
\hline MIPS2 & 3 & + & + & $(3 / 3)$ & 13.79 & 26.34 & $(2 / 3)$ & 28.31 & $(2 / 3)$ & $N^{f}$ & $(0 / 3)$ \\
\hline MIPS3 & 3 & + & + & $(3 / 3)$ & 13.40 & 24.12 & $(3 / 3)$ & 26.41 & $(2 / 3)$ & ND & $(0 / 3)$ \\
\hline MIPS4 & 3 & - & + & $(3 / 3)$ & 12.62 & 26.92 & $(3 / 3)$ & 29.06 & $(1 / 3)$ & ND & $(0 / 3)$ \\
\hline MIPS5 & 3 & + & + & $(3 / 3)$ & 14.77 & 20.62 & $(3 / 3)$ & 23.39 & $(2 / 3)$ & ND & $(0 / 3)$ \\
\hline MIPS6 & 3 & + & + & $(3 / 3)$ & 12.80 & 26.81 & $(3 / 3)$ & 28.86 & $(2 / 3)$ & ND & $(0 / 3)$ \\
\hline MIPS7 & 3 & + & $\mathrm{NC}$ & $(3 / 3)$ & 14.28 & 17.23 & $(2 / 3)$ & 20.14 & $(1 / 3)$ & ND & $(0 / 3)$ \\
\hline MIPS8 & 3 & + & $\mathrm{NC}$ & $(2 / 3)$ & 14.47 & 27.43 & $(2 / 3)$ & 30.49 & $(2 / 3)$ & ND & $(0 / 3)$ \\
\hline MIPS9 & 3 & + & + & $(2 / 3)$ & 14.10 & 28.78 & $(2 / 3)$ & 31.23 & $(3 / 3)$ & ND & $(0 / 3)$ \\
\hline MIPS11 & 3 & - & + & $(3 / 3)$ & 13.04 & 24.55 & $(3 / 3)$ & 27.29 & $(2 / 3)$ & ND & $(0 / 3)$ \\
\hline MIPS12 & 1 & - & + & $(1 / 1)$ & 14.12 & 24.13 & $(1 / 1)$ & 26.93 & $(1 / 1)$ & ND & $(0 / 1)$ \\
\hline ONPS1 & 3 & + & + & $(2 / 3)$ & 15.16 & 23.87 & $(3 / 3)$ & 27.55 & $(3 / 3)$ & ND & $(0 / 3)$ \\
\hline ONPS2 & 2 & + & + & $(1 / 2)$ & 14.59 & 23.92 & $(2 / 2)$ & 27.66 & $(2 / 2)$ & ND & $(0 / 2)$ \\
\hline ONPS3 & 3 & + & + & $(3 / 3)$ & 16.94 & 17.89 & $(3 / 3)$ & 21.98 & $(2 / 3)$ & ND & $(0 / 3)$ \\
\hline ONPS4 & 2 & + & + & $(2 / 2)$ & 17.33 & 28.35 & $(2 / 2)$ & 29.43 & $(2 / 2)$ & ND & $(0 / 2)$ \\
\hline ONPS5 & 2 & - & + & $(0 / 2)$ & 15.20 & ND & $(0 / 2)$ & ND & $(0 / 2)$ & ND & $(0 / 2)$ \\
\hline ONPS6 & 2 & - & + & $(2 / 2)$ & 15.87 & 26.33 & $(2 / 2)$ & 28.82 & $(2 / 2)$ & ND & $(0 / 2)$ \\
\hline
\end{tabular}

${ }^{a} P$. sojae isolation on semiselective medium (CMA-PARPB)

${ }^{\mathrm{b}}$ Enzyme linked immunosorbent assay for Phytophthora was conducted in plant tissues collected. NC $=$ not conclusive due to weak reaction.

${ }^{c}$ Number of positive samples detected with qPCR Phytophthora genus assay as defined as Bustin et al. (2009).

${ }^{\mathrm{d}} \mathrm{C}_{\mathrm{t}}=$ Cycle threshold values for qPCR.

e Number of positive samples out of total samples evaluated with RPA assay.

${ }^{\mathrm{f}} \mathrm{ND}=$ Not detected.

Table 4. Multiplex qPCR evaluation for Phytophthora genus and Phytophthora sojae and P. sansomeana species-specific assays of plant samples collected across nine soybean producing states in the U.S. in 2014

\begin{tabular}{|c|c|c|c|c|c|c|c|c|c|}
\hline \multirow[b]{2}{*}{ State } & \multirow[b]{2}{*}{ Fields } & \multirow[b]{2}{*}{ Positives qPCR genus ${ }^{a}$} & \multirow{2}{*}{$\frac{\text { Plant internal control }}{\text { Mean } \mathbf{C}_{\mathbf{t}} \mathbf{b}}$} & \multicolumn{2}{|c|}{$\begin{array}{c}\text { Phytophthora } \\
\text { genus }\end{array}$} & \multicolumn{2}{|c|}{ P. sojae } & \multicolumn{2}{|c|}{ P. sansomeana } \\
\hline & & & & Mean $C_{t}$ & $\mathbf{R P A}^{\mathbf{c}}$ & Mean $C_{t}$ & RPA & Mean $C_{t}$ & RPA \\
\hline \multirow[t]{3}{*}{ Arkansas } & ARPS2_1 & $(3 / 3)$ & 16.18 & 28.17 & $(2 / 3)$ & 28.99 & $(2 / 3)$ & 31.26 & $(0 / 3)$ \\
\hline & ARPS2_2 & $(1 / 3)$ & 18.84 & 29.37 & $(1 / 3)$ & 32.48 & $(0 / 3)$ & 33.87 & $(0 / 3)$ \\
\hline & ARPS2_3 & $(2 / 3)$ & 14.27 & 28.51 & $(1 / 3)$ & $\mathrm{ND}^{\mathrm{d}}$ & $(0 / 3)$ & 33.34 & $(0 / 3)$ \\
\hline \multirow[t]{2}{*}{ Iowa } & IAPS2_1 & $(0 / 4)$ & 19.33 & ND & $(1 / 4)$ & ND & $(0 / 4)$ & ND & $(0 / 4)$ \\
\hline & IAPS2_2 & $(0 / 3)$ & 19.69 & ND & $(1 / 3)$ & $\mathrm{ND}$ & $(0 / 3)$ & ND & $(0 / 3)$ \\
\hline \multirow[t]{4}{*}{ Illinois } & ILPS2_1 & $(3 / 3)$ & 17.61 & 26.13 & $(3 / 3)$ & 27.82 & $(1 / 3)$ & ND & $(0 / 3)$ \\
\hline & ILPS2_2 & $(2 / 3)$ & 18.36 & 28.09 & $(1 / 3)$ & 31.54 & $(1 / 3)$ & ND & $(0 / 3)$ \\
\hline & ILPS2_3 & $(1 / 3)$ & 22.81 & 23.94 & $(1 / 3)$ & ND & $(0 / 3)$ & ND & $(0 / 3)$ \\
\hline & ILPS2_4 & $(1 / 3)$ & 16.26 & 21.88 & $(1 / 3)$ & $\mathrm{ND}$ & $(0 / 3)$ & 24.57 & $(0 / 3)$ \\
\hline \multirow[t]{2}{*}{ Indiana } & INPS2_1 & $(4 / 4)$ & 17.65 & 27.70 & $(1 / 4)$ & 29.16 & $(1 / 4)$ & ND & $(0 / 4)$ \\
\hline & INPS2_2 & $(2 / 3)$ & 16.95 & 28.15 & $(1 / 3)$ & 30.82 & $(1 / 3)$ & 29.76 & $(0 / 3)$ \\
\hline \multirow[t]{2}{*}{ Kansas } & KSPS2_1 & (4/4) & 18.90 & 22.98 & $(3 / 4)$ & 25.00 & $(2 / 4)$ & ND & $(0 / 4)$ \\
\hline & KSPS2_2 & $(1 / 3)$ & 19.18 & 27.60 & $(1 / 3)$ & 30.52 & $(0 / 3)$ & ND & $(0 / 3)$ \\
\hline \multirow[t]{3}{*}{ Michigan } & MIPS2_1 & $(2 / 3)$ & 20.68 & 28.17 & $(2 / 3)$ & 29.60 & $(1 / 3)$ & ND & $(0 / 3)$ \\
\hline & MIPS2_2 & $(3 / 4)$ & 18.84 & 28.30 & $(2 / 4)$ & 30.06 & $(0 / 4)$ & ND & $(0 / 4)$ \\
\hline & MIPS2_3 & $(3 / 3)$ & 16.63 & 29.21 & $(0 / 3)$ & 30.25 & $(0 / 3)$ & ND & $(0 / 3)$ \\
\hline \multirow[t]{3}{*}{ N. Dakota } & NDPS2_1 & $(3 / 3)$ & 15.71 & 27.44 & $(1 / 3)$ & 28.88 & $(1 / 3)$ & ND & $(0 / 3)$ \\
\hline & NDPS2_2 & $(2 / 3)$ & 17.72 & 25.80 & $(1 / 3)$ & 25.30 & $(1 / 3)$ & ND & $(0 / 3)$ \\
\hline & NDPS2_3 & $(1 / 3)$ & 15.69 & 26.53 & $(1 / 3)$ & 25.82 & $(1 / 3)$ & ND & $(0 / 3)$ \\
\hline \multirow[t]{2}{*}{ Nebraska } & NEPS2_1 & $(2 / 3)$ & 19.70 & 25.57 & $(1 / 3)$ & 27.46 & $(2 / 3)$ & ND & $(0 / 3)$ \\
\hline & NEPS2_2 & $(3 / 3)$ & 20.24 & 22.82 & $(3 / 3)$ & 24.93 & $(3 / 3)$ & ND & $(0 / 3)$ \\
\hline \multirow[t]{2}{*}{ S. Dakota } & SDPS2_1 & $(3 / 3)$ & 17.40 & 24.96 & $(3 / 3)$ & 26.78 & $(3 / 3)$ & ND & $(0 / 3)$ \\
\hline & SDPS2_2 & $(3 / 3)$ & 17.09 & 22.76 & $(2 / 3)$ & 24.70 & $(2 / 3)$ & ND & $(0 / 3)$ \\
\hline
\end{tabular}

${ }^{a}$ Number of positive samples detected with qPCR Phytophthora genus assay as defined as Bustin et al. (2009).

${ }^{\mathrm{b}} \mathrm{C}_{\mathrm{t}}=$ Cycle threshold values for qPCR.

${ }^{\mathrm{c}}$ Number of positive samples out of total samples evaluated with RPA assay.

${ }^{\mathrm{d}} \mathrm{ND}=$ Not detected. 
been reported infecting different hosts within the U.S., isolates from different host plants were sequenced and aligned. In this case, we observed SNPs that separated $P$. sansomeana isolates from Douglas-fir and other hosts from those obtained from soybean and corn (Supplementary Fig. S1 and Supplementary Sequence S1). These SNPs were taken into account when designing the probe to allow for detection of $P$. sansomeana infecting any host.

For $P$. sojae, only one TaqMan probe was evaluated since there was no variation in the isolates observed across the locus, whereas two probes that annealed at different locations of the atp9-nad9 spacer were designed and tested for $P$. sansomeana (Table 1 and Supplementary Table S4). The probe selected for $P$. sansomeana was able to detect isolates from different hosts, ensuring amplification of all known genotypes. In addition, the Phytophthora genus-specific probe labeled with FAM and the $P$. sojae species-specific probe labeled with HEX were modified to include an internal quencher, to reduce background signal.

Sensitivity and specificity of qPCR for species-specific. To determine the specificity of the species-specific assays, a panel of Phytophthora spp. representing 96 valid taxa and 14 provisional species across the different clades of this genus, 21 Pythium spp. and Phytopythium vexans were included to test the assay specificity. No amplification was observed from any of the nontarget Phytophthora spp., including those in Clade 7 and Clade 8 where $P$. sojae and $P$. sansomeana are contained, respectively. There was consistent amplification of the target sequences from both species and cross amplification was not detected between the speciesspecific assays with the genera Pythium and Phytopythium.

A serial dilution of total DNA of $P$. sojae and $P$. sansomeana was used to determine the sensitivity of the assay. A linear correlation of all of the probes tested with the concentration of DNA for the respective pathogen was observed (Fig. 1 and Supplementary Fig. S2), resulting in corresponding amplification efficiencies of $101 \%$ for P. sansomeana, $95 \%$ for P. sojae, and $96 \%$ for Phytophthora genus assay. The LOD for quantification purposes, which is defined by consistent amplification of replicates at the lowest concentration of the standards used, was established for Phytophthora genus (LOD $\left.\mathrm{C}_{\mathrm{t}}=28\right), P$. sojae $\left(\right.$ LOD $\left.\mathrm{C}_{\mathrm{t}}=32\right)$, and $P$. sansomeana $\left(\right.$ LOD $\mathrm{C}_{\mathrm{t}}=$ 31). All of these LOD thresholds were established at $100 \mathrm{fg}$ of pure total DNA for the respective species and represented the limit of $\mathrm{C}_{t}$ values for accurate quantification, based on MIQE guidelines (Bustin et al. 2009) as defined by $>95 \%$ amplification of samples (100\% observed in this study) for the lowest amount of target DNA (Fig. 2). However, detection can occur above these $C_{t}$ thresholds, indicating the presence of the pathogen at low concentrations (Fig. 2). In addition, the presence of plant DNA, specifically soybean, did not affect assay performance (Supplementary Fig. S3). There was no difference between uniplex or multiplex amplifications; therefore, all the reactions including standards were run under multiplex conditions. For instance, the Phytophthora genus assay had efficiency of $96.5 \%$ in uniplex versus $95.6 \%$ in multiplex assay, maintaining the assay conditions within MIQE guidelines (Fig. 2). No evidence of crossreactivity was detected.

Cross-platform validation. Three different $\mathrm{qPCR}$ platforms were evaluated using the serial standard diluted DNA for both pathogens to test for assay consistency. Assay conditions were the same across the platforms. Overall amplification efficiencies ranged from 93.1 to $100.8 \%$ for the Phytophthora genus assay, from 95.3 to $95.9 \%$ for P. sojae, and 100 to $101 \%$ for P. sansomeana, indicating minimal variation across platforms (Table 5). However, the P. sansomeana probe was not useful with the StepOnePlus system since the fluorophore Quasar670 has a spectral absorption at $650 \mathrm{~nm}$ and emission at $670 \mathrm{~nm}$, which is not detected by this system. In all the platforms, the respective software set the $C_{t}$ threshold. The StepOnePlus platform exhibited high background noise that was resolved by adjusting the baseline from cycle 3 to 14 .

Field application of qPCR. The developed multiplex assay was used to diagnose soybean seedling samples collected in Michigan and Ontario in 2013 (Table 3), and across different soybean producing states in 2014, including Arkansas, Iowa, Illinois, Indiana, Kansas, Michigan, Nebraska, North Dakota, and South Dakota (Table 4). In 2013, $P$. sojae was isolated from the soybean tissue collected

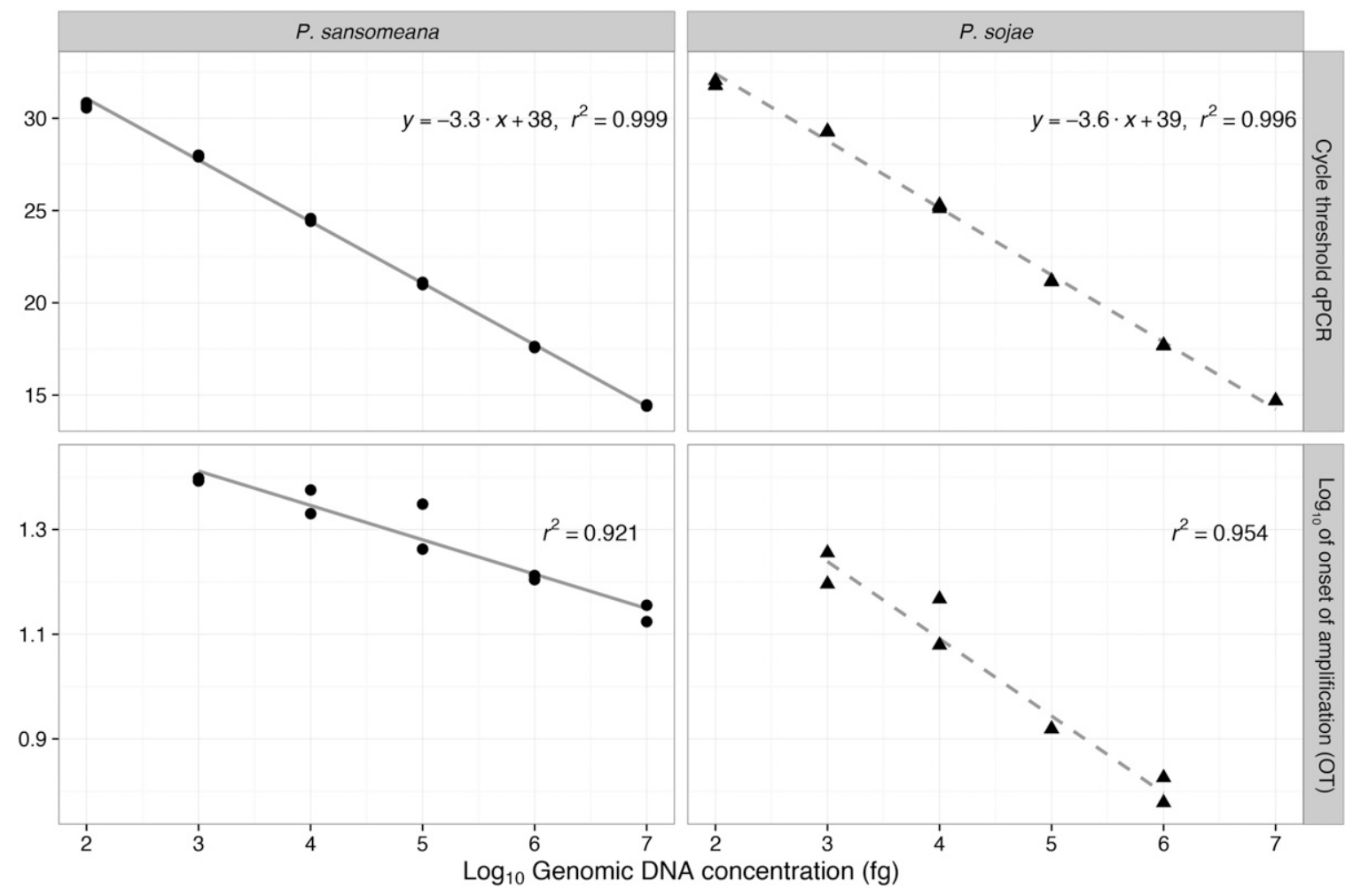

Fig. 1. Standard curve for Phytophthora sojae and $P$. sansomeana total DNA (fg) using the qPCR assay (top panels) and recombinant polymerase amplification (RPA) atp9-nad9 species-specific assay (bottom panels). Total DNA was 10 -fold diluted and the sensitivity was determined to be $100 \mathrm{fg}\left(2 \log _{10}\right)$ for qPCR and $1 \mathrm{pg}\left(3 \log _{10}\right)$ for RPA. Three technical repeats for each DNA concentration on the qPCR and two technical repeats were used for RPA. 
from 7 out of 10 sampled Michigan fields; however, no isolates of $P$. sansomeana were obtained from these field locations (Table 3). In samples collected from Ontario, $P$. sojae was isolated from four out of six sampled locations. Subsamples from plant tissue were tested with the Phytophthora ELISA assay from AGDIA. The ELISA resulted in eight positive samples for Michigan and six positive samples for Ontario. However, the Phytophthora ELISA assay did not produce conclusive results with weak reactions below threshold for two samples from which $P$. sojae were isolated.

The multiplex qPCR assay resulted in amplification of the plant internal control with $C_{t}$ values ranging from 12.6 to 17.3 , indicating amplifiable template could be generated from these extracted DNAs, thereby reducing the possibility of false negatives due to amplification inhibition (Table 3). For the Phytophthora genus assay, $\mathrm{C}_{\mathrm{t}}$ values ranged from 17.2 to 28.8 with four fields where the pathogen was not cultured but there was a positive $\mathrm{qPCR}$ result. The $P$. sojae assay resulted in $C_{t}$ values ranging from 20.1 to 31.2, in three fields in Michigan that were negative for isolation, but had a positive qPCR result. One Ontario field (ONPS5) was positive for ELISA but Phytophthora was not detected using the molecular assays even though there was a positive amplification for the plant internal control. The rest of the samples were positive for both the Phytophthora genus and $P$. sojae assay. With respect to the $P$. sansomeana assay, positive results were not obtained for any of the fields evaluated in 2013 .

In 2014, 23 fields were sampled resulting in 73 plant samples evaluated with the multiplex qPCR assay. Amplification of the plant internal control was detected for all of the samples and the Phytophthora genus-specific assay resulted in 21 positive fields with the remaining two samples having no amplification for the Phytophthora genus- and species-specific assays (Table 4). Among the 21 positive fields for the genus-specific assay, 18 fields were positive using the $P$. sojae assay, where one sample had a $\mathrm{C}_{\mathrm{t}}$ of 32 , reflecting a low titer of the pathogen. Amplification using the $P$. sansomeana assay detected this pathogen in plant samples from fields ARPS2_1, ARPS2_2, ARPS2_3, ILPS2_4, and INPS2_2 (Table 4). Three samples were also positive for $P$. sojae, indicating the presence of both pathogens in these plants. Only one sample produced amplification for the genus-specific assay, but it was negative for both speciesspecific assays. The DNA sequence of the species-specific amplicon indicates it is an undescribed species similar to Phytophthora megakarya (Supplementary Sequence S2).

Soil samples were collected from the same locations as the plant samples and evaluated using the multiplex qPCR assay to determine the presence of the pathogens. In 2013, three different types of DNA extraction treatments were applied to soil samples: undiluted, 10-fold diluted, and a paramagnetic bead-purified DNA fraction from the undiluted sample (Supplementary Table S6). For all the reactions, an internal control was used to determine presence of PCR inhibitors that could affect amplification. Overall, amplification of the internal control was detected in all reactions, but $C_{t}$ values were improved by either diluting samples or using the paramagnetic bead purified DNA as template. With respect to detection of pathogens, the Phytophthora genus- and species-specific assays resulted in detectable amplification (genus assay $\mathrm{C}_{\mathrm{t}}$ ranging from 25 to 35 ; species-specific assay ranging from 27 to 37). But most $C_{t}$ values were greater than 30 and above the LODs, so an accurate quantification of the amount of pathogen present in the soil could not be made. Although $\mathrm{C}_{\mathrm{t}}$ values improved with paramagnetic bead purification, those $\mathrm{C}_{\mathrm{t}}$ remained higher than 30 . A $\mathrm{C}_{\mathrm{t}}$ below the LOD for $P$. sojae by the genus- and species-specific assay was obtained only for MIPS9 soil samples following purification with paramagnetic beads. The use of diluted soil DNA as template delayed amplification and increased the $C_{t}$ values in most

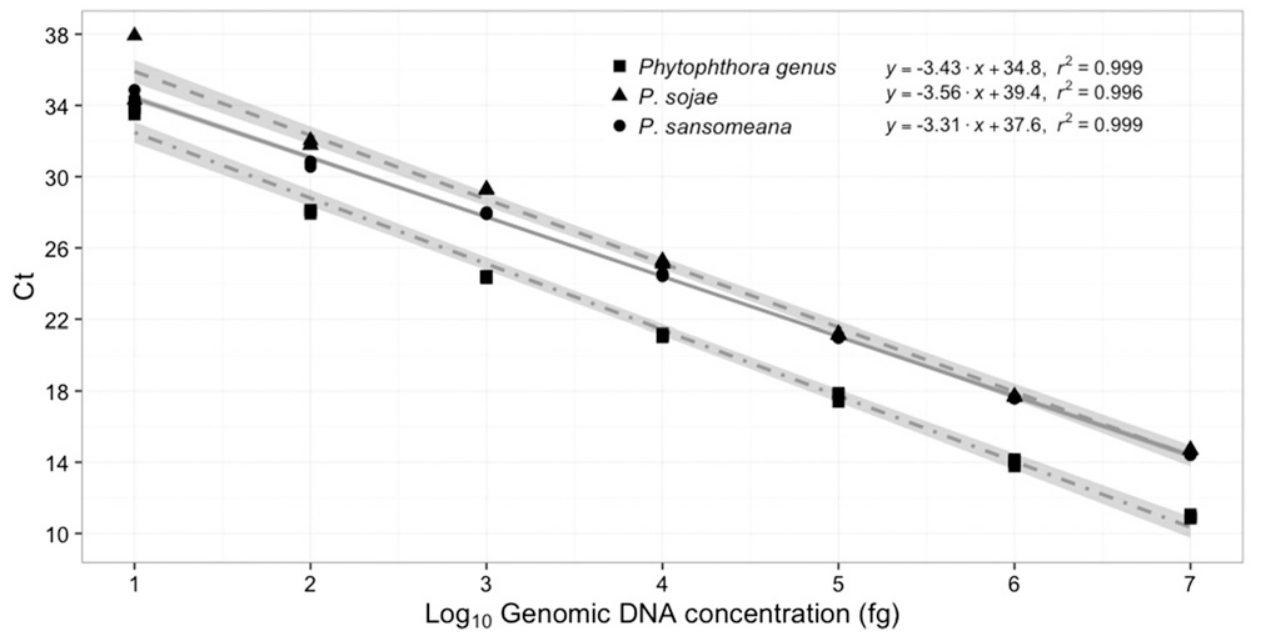

Fig. 2. Standard curve for Phytophthora genus, $P$. sojae, and $P$. sansomeana on total DNA (fg) using the multiplex qPCR assay. Total DNA was 10-fold diluted and the sensitivity was determined to be $100 \mathrm{fg}\left(2 \log _{10}\right)$ for qPCR, as $>95 \%$ (100\% observed) of standards amplified consistently as designated by Bustin et al. (2009). Squares represent Phytophthora genus, triangles represent $P$. sojae, and circles represent $P$. sansomeana.

Table 5. Cross-platform validation of Phytophthora genus and Phytophthora sojae and P. sansomeana species-specific probes

\begin{tabular}{|c|c|c|c|c|c|}
\hline Probe & Platforms & Efficiency $(\%)$ & Slope & Intercept & $\mathbf{R}^{2}$ \\
\hline \multirow[t]{3}{*}{ Phytophthora genus (FAM labeled probe) } & Step One Plus (ABI) & 100.78 & -3.30 & 38.16 & 0.99 \\
\hline & LightCycler 96 (Roche) & 100.00 & -3.31 & 35.70 & 0.92 \\
\hline & CFX96 (Bio-Rad) & 95.60 & -3.43 & 34.80 & 0.99 \\
\hline \multirow[t]{3}{*}{ P. sojae (HEX labeled probe) } & Step One Plus (ABI) & 95.325 & -3.44 & 41.175 & 0.99 \\
\hline & LightCycler 96 (Roche) & 95.50 & -3.56 & 39.35 & 1 \\
\hline & CFX96 (Bio-Rad) & 95.99 & -3.42 & 38.746 & 0.99 \\
\hline \multirow[t]{3}{*}{ P. sansomeana (Quasar670 labeled probe) } & Step One Plus (ABI) & $\mathrm{NC}^{\mathrm{a}}$ & $\mathrm{NC}$ & $\mathrm{NC}$ & $\mathrm{NC}$ \\
\hline & LightCycler 96 (Roche) & 100.50 & -3.31 & 37.59 & 1 \\
\hline & CFX96 (Bio-Rad) & 100.54 & -3.31 & 37.59 & 0.99 \\
\hline
\end{tabular}

${ }^{\mathrm{a}} \mathrm{NC}=$ Not compatible due to the use of fluorophore Quasar670 (emission $=670 \mathrm{~nm}$ ) outside of Step One Plus filter set range $(\sim 520$ to $610 \mathrm{~nm})$. 
cases, except for sample ONPS1, which actually resulted in detectable amplification in comparison with no detection in the undiluted sample. Soil DNA samples from 2014 were further purified with paramagnetic bead purification. These samples revealed a low level of the pathogen with a $C_{t}$ around or higher than 32 cycles (Supplementary Table S7).

Recombinase polymerase amplification. The development of a recombinase polymerase amplification (RPA) species-specific assay for $P$. sojae and $P$. sansomeana was based on the alignment noted above for designing the qPCR species-specific assay. The criteria for the selection of the primers was initially based on performance using total DNA, followed by a preliminary specificity test with closely related species. Since primer design for RPA assays are not as straight forward as designing PCR primers, multiple primers were tested for species specificity. In total, 10 reverse primers of different length were designed for $P$. sojae (Supplementary Table S8), and evaluated in combination with the general Phytophthora forward primer designed by Miles et al. (2015). The selected primer Psoj_n9_rev_twexo9 has a length of 29 bp and GC\% content of 17.2. In the case of $P$. sansomeana, only six primers were tested, and the best performing primer was Psan_n9_rev_twexo1 with a length of $35 \mathrm{bp}$ and GC\% content of 14.3. Both primers were assessed against the panel of Phytophthora spp., Phytopythium vexans, and Pythium spp., resulting in no cross amplification with any of the nontarget taxa.

To test the sensitivity of the RPA assay, a 10 -fold $P$. sojae or $P$. sansomeana total DNA serial dilution from $10 \mathrm{ng}$ to $1 \mathrm{pg}$ was tested in independent RPA reactions; DNA concentrations below this level were not detected. The $\log 10$ of the onset of amplification, namely the time at which the reaction meets the criteria for the slope validation, was plotted against the log concentration of the total DNA. While the $P$. sojae RPA assay amplification occurred between 6 and 18 min, depending on the concentration, with an $\mathrm{R}^{2}$ value of 0.954 (Fig. 1), amplification for the P. sansomeana RPA assay occurred between 12 and 24 min with an $\mathrm{R}^{2}$ value of 0.921 (Fig. 1). The lowest concentration for a positive detection for both assays was between $10 \mathrm{pg}$ to $1 \mathrm{pg}$.

Field application of RPA genus- and species-specific assays. Plant samples collected in 2013 and 2014 were divided for both qPCR and RPA testing. A total of 115 plant samples were evaluated, 42 in 2013 and 73 in 2014. From the 42 samples obtained in 2013, 36 resulted in positive amplification by the Phytophthora genus RPA assay, of which 29 were also positive for detection of $P$. sojae using the RPA species-specific assay (Table 3). From 73 samples tested in 2014, 34 were positive for detection with the Phytophthora genusspecific assay of which 22 were positive with the $P$. sojae RPA assay (Table 4). In both years, $P$. sansomeana was not detected in any plant samples.

Sensitivity of the RPA genus- and species-specific assays was evaluated in contingency tables in comparison with the qPCR genus assay using the number of true positives (positive for qPCR and RPA) divided by the sum of true positives (positive for qPCR and RPA) and false RPA negatives (positive qPCR, but negative for RPA). Out of 115 samples, the RPA genus assay resulted in an overlap of 70 samples designated as true positives, and only 15 samples designated as false negatives (positive for qPCR but negative for RPA). Results from the RPA genus-specific assay correlated with the qPCR assay $82.4 \%$ of the time. There were four samples designated possible false positives (negative with qPCR, and positive with RPA) and 26 were samples designated as true negatives. Out of the 115 samples at the species level, 51 samples were designated as true positives, 34 samples were designated as false negatives, resulting in a correlation between RPA and qPCR of $60.4 \%$ for species-specific detection. Both assays coincided in 30 samples being designated as true negatives for the species assay, indicating no issues with specificity.

\section{Discussion}

We developed a multiplex hierarchical genus- and species-specific qPCR assay, utilizing the Phytophthora genus assay developed by Bilodeau et al. (2014), which simultaneously determines if a sample is infected by any Phytophthora spp. in addition to determining if the sample is infected with either $P$. sojae, $P$. sansomeana, or both. The assay is specific to these two species as tested against a panel of 110 different Phytophthora taxa (including valid and provisional species) and other oomycete species that could be associated with roots of soybean plants. In addition, the assay exhibited a high sensitivity consistently detecting as little as $100 \mathrm{fg}$ of $P$. sojae or $P$. sansomeana DNA. The assay also includes a plant mitochondrial internal control to determine if the presence of PCR inhibitors could inhibit amplification, thereby controlling for failed amplifications. To allow the use of this assay on soil samples, an artificial internal control was added to the master mix to monitor the effect of PCR inhibitors on amplification efficiency as reported by Bilodeau et al. (2012). Furthermore, the qPCR assay was cross-validated on different platforms in laboratories in Michigan and California, demonstrating the transferability of the assay.

The selection of the DNA target plays an important role in assay sensitivity and specificity, and in this case, the mitochondrial region between the atp9-nad 9 was identified as harboring enough variation to generate species-specific probes for different Phytophthora spp. (Bilodeau et al. 2014; Miles et al. 2015, 2017). Both TaqMan probes, primers, and RPA primers have already been validated for this mitochondrial locus, which will allow us to utilize this atp9-nad 9 marker system on a variety of crops outside of soybeans as demonstrated by Miles et al. (2017). In comparison with other assays that target multicopy genes or genomic regions like rDNA in fungal pathogens (Bilodeau et al. 2012; Schena et al. 2013; Wang et al. 2015), the current assays targeting the mitochondrial DNA are very sensitive due to the presence of multiple mitochondria per cell; however, it is unknown if there is consistency in the numbers of mitochondria per cell during different phases of plant infection and survival in soil; this should be evaluated further prior to using this locus for pathogen quantification. The LOD was calculated for all assays where $C_{t}=$ 28 for the genus-specific marker and $C_{t}=31$ to 32 for the respective species-specific markers. Previous research with the atp9-nad9 Phytophthora marker system and working with other species has shown that the LOD can vary with the genus-specific $C_{t}$ value being as high as 33.1 (i.e., for P. ramorum) and the species-specific $\mathrm{C}_{\mathrm{t}}$ value being as high as 35.7 (i.e., $P$. ramorum) (Miles et al., unpublished).

The use of the multiplex qPCR resulted in the detection of $P$. sojae in soybean plants collected from 33 out 39 fields. While the sampling was targeted toward Phytophthora stem and root rot symptomatic fields, it agrees with the broad presence of $P$. sojae reported in other studies (Dorrance et al. 2016). With respect to $P$. sansomeana, fields in Arkansas, Indiana, and Illinois were designated as positive, which highlights the distribution of this recently described species. The tools reported in this study will be of great help to confirm the presence and impact of $P$. sansomeana in soybean and corn fields, since reports of its recovery in some states, like Wisconsin, are increasing (Phibbs et al. 2014). In 2013, isolations of $P$. sojae from symptomatic plants were performed and results corroborated the qPCR detection. There were four cases out of five where $P$. sojae was not isolated, but it was detected with the qPCR assay. These results provided support for the reliability of the assay, and reinforced the advantage of using molecular diagnostics to establish the presence of pathogen. The plant internal control was amplified from all plant tissue DNA extractions, reducing the likelihood that inhibitors were preventing amplification. However, this type of internal control does not evaluate the influence of PCR inhibitors on amplification efficiency, so it is possible that pathogen detection was impacted if pathogen target DNA was present at low amounts, resulting in false negatives. Samples that were positive for the qPCR genus assay, but negative for the species-specific qPCR assay, were sequenced to determine the if there were issues with specificity; the resulting sequences were negative for $P$. sojae and $P$. sansomeana, confirming the specificity of the assay.

In addition to the field samples reported in the current study, the multiplex qPCR assay was also used on diagnostic samples submitted to and in collaboration with the Michigan State University Diagnostic Laboratory (data not shown). Four samples were subsampled and processed into three different tissues (tap root, lateral roots, and 
stem) and analyzed in the CFX-96 (Bio-Rad platform). From these, two samples were positive for both pathogens. The processing of these samples by tissue type (tap root, lateral roots, and stem) demonstrated a trend where $P$. sojae infected primarily stem and lateral roots, while $P$. sansomeana infected tap roots (data not shown). This preliminary data suggests spatial variation on the infection of these pathogens; however, this requires further evaluation. The availability of these tools can be used in conjunction with microscopy to track the pathogen infection as reported in other pathosystems (MartínRodrigues et al. 2013).

When evaluating soil samples with the qPCR assay, it was apparent that additional template cleanup was needed to eliminate the influence of PCR inhibitors on the sensitivity and accuracy of data collection. Amplification of the internal control was inhibited in many soil samples following DNA extraction with just the FastDNA SPIN kit; diluting samples 1:10 improved amplification for many but not all templates. Subsequent purification of DNA extracts with paramagnetic beads further improved amplification (reduced $C_{t}$ closer to what was observed for amplification without added soil extracted DNA) for nearly all samples. The improvement in the amplification was also observed for the internal control, where in most cases there is a reduced cycle threshold that indicates better amplification conditions. Additional research on techniques to improve the quality of the extracted DNA will likely improve the sensitivity of the described assays. Other problems with developing molecular techniques for quantification of soilborne pathogens include ensuring the pathogen propagules have been disrupted in the DNA extraction procedure and that the field sampling strategy is adequate to ensure enough of the pathogen has been recovered to be detected and reflects pathogen distribution within the field. It is possible that oospores were recalcitrant to DNA extraction and further procedures are necessary to increase DNA yield; however, the extraction technique used in this experimentation was similar to what was reported for disruption of microsclerotia of Verticillium dahliae (Bilodeau et al. 2012).

Given the nonrandom distribution and low inoculum densities of many soilborne pathogens, developing a procedure to collect a representative sample from the field and economically process more than $500 \mathrm{mg}$ of soil at a time should improve assay sensitivity and reliability for estimating pathogen propagule density. The use of larger amount of samples could improve the detection since $P$. sojae may be present in a low density in the soil and plant tissue, leading to the requirement of sophisticated enrichment and isolation methods to improve the recovery of this pathogen (Dorrance et al. 2008). Soil type and composition may also influence subsequent purity of the DNA samples and may require additional screening of extraction procedures (Bilodeau et al. 2012; Okubara et al. 2005). Although $C_{t}$ values from most soil samples evaluated in the study were above the LOD determined by DNA standard curves (thereby limiting data interpretation for estimation of propagule density), some level of amplification was observed for many samples suggesting the pathogen was present but at low inoculum density. Following the above noted considerations for assay optimization, assays should also be optimized to improve pathogen DNA yield, since it has been observed that increased concentration of pathogen propagules does not ensure higher extraction and detection efficiency (Chilvers et al. 2007).

A rapid isothermal molecular assay was also developed based on the same mitochondrial locus, to discriminate between $P$. sojae and $P$. sansomeana. Using an established Phytophthora genus assay developed by Miles et al. (2015), a hierarchical approach was also used to diagnose field samples, validating the use of this novel technology to establish the presence of pathogen in plant samples directly in the field. The sensitivity of the RPA assays was around $1 \mathrm{pg}$ of total DNA from both pathogens, exhibiting high specificity, as evaluations against a panel of Phytophthora spp., Pythium spp., and Phytopythium resulted in no amplification of the nontarget species.

The RPA assay was not as sensitive as previously reported. Lot variability in fluorometric RPA exo kit amplification was observed over the course of these experiments, and during this process we identified several factors that impacted assay performance. While Miles et al. (2015) reported sensitivities between 200 and $300 \mathrm{fg}$ of
DNA, the experiments reported in this manuscript show sensitivity of 1 to $10 \mathrm{pg}$. After discussions with the manufacturer, one factor influencing performance is likely changes in formulation resulting in changes in the ratios of enzymes involved in amplification in the current kits available. To overcome the changes in chemistry, additional optimization of assay conditions to improve detection sensitivity should be conducted. The approaches could encompass magnesium to optimize amplification conditions and DNA concentration. For example, preliminary data showed that increasing the magnesium concentration in the $P$. sojae RPA assay improved amplification sensitivity. Currently, there are two manufacturers of RPA kits (Twistdx Inc. and Agdia Inc.) creating products with different overall reaction volumes (50 and $25 \mu$ l, respectively). Limited field samples from the current study were also evaluated with Agdia Inc. kits, and these produced consistent results (data not shown).

The reduced sensitivity is likely the reason for false negatives in the RPA assay when qPCR results were positive. Many of these samples had a high $\mathrm{Ct}$ in the $\mathrm{qPCR}$ assay indicating a low pathogen DNA concentration. To overcome some of these issues, we suggest the comparison of different amounts of tissue for extraction or adding a larger amount of sample extract to the amplification reaction. The sample handling and extraction conditions were also different in the current study compared with Miles et al. (2015); due to time limitation and the number of samples to process, the tissue used for RPA amplification was placed fresh into a freezer at $-20^{\circ} \mathrm{C}$ and removed at a later time for maceration in buffer, whereas in Miles et al. (2015) the tissue was macerated fresh. It is possible that during the slow freezing and subsequent thaw step prior to maceration that some of the target DNA may have been degraded, which would reduce detection sensitivity. Trials processing samples fresh, flash freezing in liquid nitrogen, or freeze-drying may provide more optimal conditions for pathogen DNA extraction. Nonetheless, the RPA assay was designed to be used in the field, therefore there is no need for freezing or drying plant material.

The primer development for RPA is also critical in assay optimization, and although this is not well characterized, different primer lengths may help to improve the assay performance (Boyle et al. 2014). We observed that different primer lengths had different behavior on the two species. For example, in our case $P$. sojae with the 29-mer primer assay had a faster amplification than the P. sansomeana assay with a 35-mer primer, but both of them were the best among the primers tested. The primers developed in this study in conjunction with primers from other studies will be important to develop criteria and guidelines for optimal RPA primer design and reaction conditions.

Both qPCR and RPA assays were validated with soybean samples collected in commercial fields in 2013 and 2014, demonstrating the applicability of the assays to detect Phytophthora in soybean fields. While the RPA assay demonstrated similar levels of detection at the genus level, the sensitivity at species level detection was lower. In addition, Miles et al. (2017) developed primers that allow the sequencing of amplicons in positive samples or those that result in amplification on either the qPCR or RPA assay. The fragment could be aligned to the atp9-nad 9 sequences (Bilodeau et al. 2014; Miles et al. 2017), facilitating the identification of the potential Phytophthora spp. As previously noted, further optimization of sample processing (using larger amounts of fresh tissue) should improve the sensitivity of the RPA assay. The fact that different parts of the plant were processed for the qPCR and RPA assays may have also contributed to inconsistencies in results when comparing these two assays. Nevertheless, the rapid detection of the isothermal assay provides a tool with the potential to diagnose field samples on site in just 20 to $40 \mathrm{~min}$ and to be more sensitive than culture based techniques. The results obtained with field samples using the $P$. sojae RPA assay indicate the utility of the method in comparison with the qPCR assay. The RPA assays are more tolerant of inhibitors, and as such crude extract rather than purified DNA can be used as template (Craw and Balachandran 2012). For instance, food and tissue samples processed with isothermal techniques, such as RPA, have demonstrated consistent amplification when compared with real-time quantitative PCR, which 
is affected by different inhibitors present in the samples (Kim and Lee 2016). In addition, the availability of different and inexpensive platforms, such as the portable and battery operable BioRanger (formerly Smart-DART; Diagenetix Inc.), facilitates the rapid and robust detection of pathogens directly in the field (Jenkins et al. 2011).

The qPCR and RPA assays were presented in a diagnostician workshop as part of the North Central-APS meeting in 2015, and the assays were demonstrated and used by a variety of diagnosticians and researchers (Wang et al. 2016). In addition, a webcast was recorded on the Plant Health Management Network, where both qPCR and RPA assay basics and the development of $P$. sojae and $P$. sansomeana assays were discussed (Rojas 2016). These tools will help diagnostic clinics and researchers throughout soybean growing regions to identify more quickly and accurately $P$. sojae and $P$. sansomeana. The Phytophthora species-specific qPCR and RPA assays presented in the current study allow the accurate, sensitive, and specific detection of $P$. sojae and $P$. sansomeana within the limits of the corresponding technology. Using molecular detection tools more routinely will provide clearer insights into the epidemiology of $P$. sojae and $P$. sansomeana, and it will open new avenues for the study of the infection process of these pathogens and the effect of management strategies on the abundance of these Phytophthora spp. In addition, coupling these tools with isolation data might help us identify new Phytophthora spp. that have a detrimental effect on soybean, corn, and other crops or the identification of potential host specific forms of $P$. sansomeana.

\section{Acknowledgments}

This project was supported by Agriculture and Food Research Initiative Competitive Grant No. 2011-68004-30104 from the USDA National Institute of Food, United Soybean Board, and North Central Soybean Research Program. The authors would like to thank Janette Jacobs and Jan Byrne for technical assistance and members of the Oomycete Soybean Coordinated Agricultural Project Extension Network: John Rupe (AR), Alison Robertson (IA), Carl Bradley (KY), Kiersten Wise (IN), Doug Jardine (KS), Berlin Nelson (ND), Loren Giesler (NE), Albert Tenuta, (ON, Canada), and Tom Chase (SD) for collection of samples for assay validation, and Leila Maria Costamilan and Everett Hanson for Phytophthora isolates.

\section{Literature Cited}

Agdia. 2016. User guide: ImmunoStrip ${ }^{\circledR}$ for Phytophthora. Agdia Inc. Available from: https://orders.agdia.com/assets/site/docs/m304.pdf

Bienapfl, J. C. J., Malvick, D. K. D., and Percich, J. A. J. 2011. Specific molecular detection of Phytophthora sojae using conventional and real-time PCR. Fungal Biol. 115:733-740.

Bilodeau, G. J., Koike, S. T., Uribe, P., and Martin, F. N. 2012. Development of an assay for rapid detection and quantification of Verticillium dahliae in soil. Phytopathology 102:331-343.

Bilodeau, G. J., Martin, F. N., Coffey, M. D., and Blomquist, C. L. 2014. Development of a multiplex assay for genus- and species-specific detection of Phytophthora based on differences in mitochondrial gene order. Phytopathology 104:733-748

Bowman, K. D., Albrecht, U., Graham, J. H., and Bright, D. B. 2007. Detection of Phytophthora nicotianae and P. palmivora in citrus roots using PCR-RFLP in comparison with other methods. Eur. J. Plant Pathol. 119:143-158.

Boyle, D. S., McNerney, R., Teng Low, H., Leader, B. T., Pérez-Osorio, A. C., Meyer, J. C., O'Sullivan, D. M., Brooks, D. G., Piepenburg, O., and Forrest, M. S. 2014. Rapid detection of Mycobacterium tuberculosis by recombinase polymerase amplification. PLoS One 9:e103091.

Bustin, S. A., Benes, V., Garson, J. A., Hellemans, J., Huggett, J., Kubista, M., Mueller, R., Nolan, T., Pfaffl, M. W., Shipley, G. L., Vandesompele, J., and Wittwer, C. T. 2009. The MIQE guidelines: minimum information for publication of quantitative real-time PCR experiments. Clin. Chem. 55:611-622.

Catal, M., Erler, F., Fulbright, D. W., and Adams, G. C. 2013. Real-time quantitative PCR assays for evaluation of soybean varieties for resistance to the stem and root rot pathogen Phytophthora sojae. Eur. J. Plant Pathol. 137:859-869.

Chilvers, M. I., du Toit, L. J., Akamatsu, H., and Peever, T. L. 2007. A real-time, quantitative PCR seed assay for Botrytis spp. that cause neck rot of onion. Plant Dis. 91:599-608.

Craw, P., and Balachandran, W. 2012. Isothermal nucleic acid amplification technologies for point-of-care diagnostics: a critical review. Lab Chip 12: 2469-2486.

Dai, T.-T., Lu, C.-C., Lu, J., Dong, S., Ye, W., Wang, Y., and Zheng, X. 2012. Development of a loop-mediated isothermal amplification assay for detection of Phytophthora sojae. FEMS Microbiol. Lett. 334:27-34.

Dorrance, A. E., Berry, S. A., Anderson, T. R., and Meharg, C. 2008. Isolation, storage, pathotype characterization, and evaluation of resistance for
Phytophthora sojae in soybean. Plant Health Prog. Online publication. doi:doi:10.1094/PHP-2008-0118-1001-DG

Dorrance, A. E., Kurle, J. E., Robertson, A. E., Bradley, C., Giesler, L., Wise, K. A., and Concibido, V. C. 2016. Pathotype diversity of Phytophthora sojae in eleven states in the United States. Plant Dis. 100:1429-1437.

Dorrance, A. E., Robertson, A. E., Cianzo, S., Giesler, L. J., Grau, C. R., Draper, M. A., Tenuta, A. U., and Anderson, T. R. 2009. Integrated management strategies for Phytophthora sojae combining host resistance and seed treatments. Plant Dis. 93:875-882.

Erwin, D. C., and Ribeiro, O. K. 1996. Phytophthora diseases worldwide. APS Press, St. Paul, MN.

Fukuta, S., Takahashi, R., Kuroyanagi, S., Ishiguro, Y., Miyake, N., Nagai, H., Suzuki, H., Tsuji, T., Hashizume, F., Watanabe, H., and Kageyama, K. 2014 Development of loop-mediated isothermal amplification assay for the detection of Pythium myriotylum. Lett. Appl. Microbiol. 59:49-57.

Fukuta, S., Takahashi, R., Kuroyanagi, S., Miyake, N., Nagai, H., Suzuki, H., Hashizume, F., Tsuji, T., Taguchi, H., Watanabe, H., and Kageyama, K. 2013. Detection of Pythium aphanidermatum in tomato using loop-mediated isothermal amplification (LAMP) with species-specific primers. Eur. J. Plant Pathol. 136:689-701

Hamm, P., and Hansen, E. 1981. Host specificity of Phytophthora megasperma from Douglas fir, soybean, and alfalfa. Phytopathology 71:65-68.

Hansen, E. M., Reeser, P. W., and Sutton, W. 2012. Phytophthora beyond agriculture. Annu. Rev. Phytopathol. 50:359-378.

Hansen, E. M., Wilcox, W. F., Reeser, P. W., and Sutton, W. 2009. Phytophthora rosacearum and $P$. sansomeana, new species segregated from the Phytophthora megasperma complex. Mycologia 101:129-135.

Hansen, Z. R., Knaus, B. J., Tabima, J. F., Press, C. M., Judelson, H. S., Grünwald, N. J., and Smart, C. D. 2016. Loop-mediated isothermal amplification for detection of the tomato and potato late blight pathogen, Phytophthora infestans. J. Appl. Microbiol. 120:1010-1020.

Jeffers, S. N. 1986. Comparison of two media selective for Phytophthora and Pythium species. Plant Dis. 70:1038-1043.

Jenkins, D. M., Kubota, R., Dong, J., Li, Y., and Higashiguchi, D. 2011. Handheld device for real-time, quantitative, LAMP-based detection of Salmonella enterica using assimilating probes. Biosens. Bioelectron. 30:255-260.

Kaufmann, M. J., and Gerdemann, J. W. 1958. Root and stem rot of soybean caused by Phytophthora sojae n.sp. Phytopathology 48:201-208.

Kim, J. Y., and Lee, J.-L. 2016. Rapid detection of Salmonella enterica serovar enteritidis from eggs and chicken meat by real-time recombinase polymerase amplification in comparison with the two-step real-time PCR. J. Food Saf 36:402-411.

Kubota, R., Vine, B. G., Alvarez, A. M., and Jenkins, D. M. 2008. Detection of Ralstonia solanacearum by loop-mediated isothermal amplification. Phytopathology 98:1045-1051.

Li, B., Liu, P., Xie, S., Yin, R., Weng, Q., and Chen, Q. 2015. Specific and sensitive detection of Phytophthora nicotianae by nested PCR and loopmediated isothermal amplification assays. J. Phytopathol. 163:185-193.

Malvick, D. K., and Grunden, E. 2004. Traits of soybean-infecting Phytophthora populations from Illinois agricultural fields. Plant Dis. 88:1139-1145.

Martin, F. N., Blair, J. E., and Coffey, M. D. 2014. A combined mitochondrial and nuclear multilocus phylogeny of the genus Phytophthora. Fungal Genet. Biol. 66:19-32.

Martín-Rodrigues, N., Espinel, S., Sanchez-Zabala, J., Ortíz, A., González-Murua, C., and Duñabeitia, M. K. 2013. Spatial and temporal dynamics of the colonization of Pinus radiata by Fusarium circinatum, of conidiophora development in the pith and of traumatic resin duct formation. New Phytol. 198:1215-1227

Miles, T. D., Martin, F. N., and Coffey, M. D. 2015. Development of rapid isothermal amplification assays for detection of Phytophthora spp. in plant tissue. Phytopathology 105:265-278.

Miles, T. D., Martin, F. N., Robideau, G. P., Bilodeau, G. J., and Coffey, M. D. 2017 Systematic development of Phytophthora species-specific mitochondrial diagnostic markers for economically important members of the genus. Plant Dis. (in press) doi: 10.1094/PDIS-09-16-1224-RE

O’Brien, P. A., Williams, N., and Hardy, G. E. S. 2009. Detecting Phytophthora. Crit. Rev. Microbiol. 35:169-181.

Okubara, P. A., Schroeder, K. L., and Paulitz, T. C. 2005. Real-time polymerase chain reaction: applications to studies on soilborne pathogens. Can. J. Plan Pathol. 27:300-313.

Phibbs, A., Barta, A., and Lueloff, S. 2014. Wisconsin pest survey report: 2008 2014 early season soybean root rot survey. Available from: http://pestsurvey. wi.gov/plantdisease/pdf/soybean/2014-2008EarlySeasonSoybeanSurvey.pdf

Piepenburg, O., Williams, C. H., Stemple, D. L., and Armes, N. A. 2006. DNA detection using recombination proteins. PLoS Biol. 4:e204.

Reeser, P., Scott, D., and Ruhl, D. 1991. Recovery of race non-classifiable Phytophthora megasperma f. sp. glycinea from soybean roots in Indiana in 1990. Phytopathology 81:1201.

Rizvi, S. S. A., and Yang, X. B. 1996. Fungi associated with soybean seedling disease in Iowa. Plant Dis. 80:57-60.

Rojas, J. A. 2016. Diagnostics tools for identification of soybean root rot diseases Available from: http://www.plantmanagementnetwork.org/edcenter/seminars/ soybean/RootRotDiagnosticsTools/ 
Rojas, J. A., Jacobs, J. L., Napieralski, S., Karaj, B., Bradley, C. A., Chase, T., Esker, P. D., Giesler, L. J., Jardine, D. J., Malvick, D. K., Markell, S. G., Nelson, B. D., Robertson, A. E., Rupe, J. C., Smith, D. L., Sweets, L. E., Tenuta, A. U., Wise, K. A., and Chilvers, M. I. 2017a. Oomycete Species Associated with Soybean Seedlings in North America-Part I: Identification and Pathogenicity Characterization. Phytopathology 107:280-292.

Rojas, J. A., Jacobs, J. L., Napieralski, S., Karaj, B., Bradley, C. A., Chase, T., Esker, P. D., Giesler, L. J., Jardine, D. J., Malvick, D. K., Markell, S. G., Nelson, B. D., Robertson, A. E., Rupe, J. C., Smith, D. L., Sweets, L. E., Tenuta, A. U., Wise, K. A., and Chilvers, M. I. 2017b. Oomycete Species Associated with Soybean Seedlings in North America-Part II: Diversity and Ecology in Relation to Environmental and Edaphic Factors. Phytopathology 107:293-304.

Schena, L., Nicosia, M. G. D., Sanzani, S. M., Faedda, R., Ippolito, A., and Cacciola, S. O. 2013. Development of quantitative PCR detection methods for phytopathogenic fungi and oomycetes. J. Plant Pathol. 95:7-24.

USDA-APHIS. 2004. Sudden oak death: Phytophthora ramorum. In: Pest Detection and Management Programs. L. Levy and V. Mavrodieva, eds. USDA Animal Plant Health Inspection Service, U.S.A.
Wang, J., Jacobs, J. L., Byrne, J. M., and Chilvers, M. I. 2015. Improved diagnoses and quantification of Fusarium virguliforme, causal agent of soybean sudden death syndrome. Phytopathology 105:378-387.

Wang, J., Rojas, J. A., Miles, T., Roth, M., Byrne, J., Jacobs, J., and Chilvers, M 2016. 2015 MSU Plant Disease Diagnostic Training Workshop. (http://dx.doi. org/10.5281/zenodo.55219)

Wang, Y., Zhang, W., Wang, Y., and Zheng, X. 2006. Rapid and sensitive detection of Phytophthora sojae in soil and infected soybeans by species-specific polymerase chain reaction assays. Phytopathology 96:1315-1321.

Wrather, A., Shannon, G., Balardin, R., Carregal, L., Escobar, R., Gupta, G. K., Ma Z., Morel, W., Ploper, D., and Tenuta, A. 2010. Effect of diseases on soybean yield in the top eight producing countries in 2006. Plant Health Prog. Online publication. doi:10.1094/PHP-2010-0125-01-RS

Yan, L., Zhou, J., Zheng, Y., Gamson, A. S., Roembke, B. T., Nakayama, S., and Sintim, H. O. 2014. Isothermal amplified detection of DNA and RNA. Mol. Biosyst. 10:970-1003.

Zelaya-Molina, L. X., Ellis, M. L., Berry, S. A., and Dorrance, A. E. 2010. First report of Phytophthora sansomeana causing wilting and stunting on corn in Ohio. Plant Dis. 94:125. 